\section{A comparison of accommodation amplitudes in pseudophakic eyes measured with three different methods}

\author{
Abstract \\ Purpose To compare the accommodative \\ amplitudes with three different methods in \\ pseudophakic eyes with different types of \\ intraocular lenses (IOLs). \\ Methods Fifty-one pseudophakic eyes of 44 \\ patients (age: $72.02 \pm 8.53$ years) were studied. \\ One of two different types of IOL were \\ implanted $\left(N=30\right.$, three-piece Alcon ${ }^{\circledR}$ \\ Acrysof $^{\circledR}$ MA60AC and $N=21$, one-piece \\ Alcon ${ }^{\circledR}$ Acrysof ${ }^{\circledR}$ SA60AT) in-the-bag after \\ standard phacoemulsification. The time of the \\ examinations was $13.85 \pm 7.35$ months \\ postoperatively. We measured the amplitude \\ of accommodation with three different \\ methods: (1) subjective minus-lenses-to-blur \\ method; (2) a new optical device (ACMaster ${ }^{\circledR}$, \\ Carl Zeiss, Jena, Germany) using partial \\ coherence interference (PCI) technique under \\ physiological stimulus; and (3) objective \\ anterior chamber depth measuring with a \\ standard A-scan ultrasonic device (Ultrascan \\ Imaging System ${ }^{\mathbb{R}}$, Alcon Laboratories, Forth \\ Worth, TX, USA) before and after \\ pharmacological relaxation of ciliary muscle. \\ Results We measured $-0.83 \pm 0.63 \mathrm{D}$ \\ amplitude of accommodation with subjective \\ minus-lenses-to-blur method. The IOL \\ position did not change significantly during \\ physiological accommodation effort measured \\ with PCI method $(-0.026 \pm 0.134 \mathrm{~mm})$. The \\ change in the IOLs position between near \\ fixating and after ciliary muscle relaxation was \\ $-0.18 \pm 0.28 \mathrm{~mm}$ measured with ultrasound. \\ There were no significant differences between \\ values of one-piece and three-piece IOL \\ groups. \\ Conclusion The amplitude of \\ accommodation measured by subjective and \\ objective methods are different and are not
}

G Nemeth1', A Tsorbatzoglou', P Vamosi²,

Z Sohajda ${ }^{3}$ and A Berta ${ }^{1}$

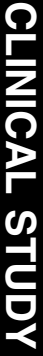

comparable with each other. We did not observe any difference between values of examined two types of IOLs.

Eye (2008) 22, 65-69; doi:10.1038/sj.eye.6702519; published online 14 July 2006

Keywords: pseudophakic accommodation; amplitude of accommodation; partial coherence interfence method

\section{Introduction}

Pseudophakic accommodation is the change in the refractive power of the eye associated with either movement and/or tilt of an intraocular lens (IOL). Pseudophakic

pseudoaccommodation refers to factors associated with good near visual acuity in patients implanted with IOLs, and can be explained by one or the combination of the following factors: minus cylinder, higher order corneal multifocality, and/or small pupil size resulting in increased depth of field. ${ }^{1-5}$ Forward movement of the implanted IOL induced by accommodative effort of the ciliary muscle has also been reported. ${ }^{6-10}$

In the recent study, we measured and assessed the amplitude of accommodation in pseudophakic eyes implanted with one of two different types of IOLs with three different methods, one subjective and two objective methods.

\section{Patients and methods}

Fifty-one pseudophakic eyes of 44 patients (age: $72.02 \pm 8.53$ years, range: $54-84$ years) were studied prospectively. Exclusion criteria were more than $1.0 \mathrm{D}$ of corneal astigmatism or any
'Department of Ophthalmology, Medical Health and Science Center, University of Debrecen, Debrecen, Hungary

${ }^{2}$ Department of Ophthalmology, Szent Rokus Hospital, Budapest, Hungary

${ }^{3}$ Department of Ophthalmology, Kenezy Gyula Hospital, Debrecen, Hungary

Correspondence: $\mathrm{G}$ Nemeth,

Department of Ophthalmology, Nagyerdei Blvd. 98,

Debrecen 4012

Hungary

Tel: + 3652415816 ;

Fax: + 3652415816

E-mail: nemeth222@

yahoo.com

Received: 14 March 2006 Accepted in revised form: 8 June 2006 Published online: 14 July 2006

Authors have no proprietary interests or conflict of interests in this study University of Debrecen, 
eye pathology affecting complete visual acuity. Standard phacoemulsifications were carried out after clear corneal incision. One of two different types of monofocal intraocular lenses (IOLs) were implanted in-the-bag. The one-piece Acrysof ${ }^{\circledR}$ SA60AT (Alcon Laboratories, Forth Worth, TX, USA) has open-loop design (group 1: $N=21$ ) without haptic angulation, the three-piece Acrysof ${ }^{\circledR}$ MA60AC (Alcon Laboratories, Forth Worth, TX, USA) has haptic angulation of $10^{\circ}$ (group 2: $N=30$ ).

After a mean of $13.85 \pm 7.35$ months of operations (group 1: $7.05 \pm 4.71$ months; group 2: $17.01 \pm 6.44$ months), we measured the amplitude of accommodation of pseudophakic eyes using three approaches in the same visit. The examinations were performed without knowing the results of the other ones. The chronological order of the three methods are: subjective minus-lensesto-blur method and objective measurement of the anterior chamber depth (ACD) with two techniques detailed below.

\section{Method 1: Subjective minus-lenses-to-blur}

The patients were asked to look at the illuminated, distant visual acuity chart number of the 20/20 line with the observed eye. With distance correction, minus diopter (D) lenses were added in front of the observed eye in 0.25 D steps. The patients reported when the 20/20 line could no longer be held in sharp focus. The maximum minus lens power added over the distance correction with which the patients can see the number in 20/20 line was recorded as the amplitude of accommodation.

\section{Method 2: ACD measurement with a new device working with partial coherence interference technique}

The ACD was measured with ACMaster ${ }^{\circledR}$ (Carl Zeiss, Jena, Germany) with built-in, movable target for physiologic near and distance fixation. All of the patients were seated and were forced to fixate to the target at near and at distance too. The device measured the fixating eye, so avoiding interference from convergence movement. The mechanism of the partial coherence interference (PCI) method has been described in details elsewhere. ${ }^{11-13}$ A mean of five measurements were recorded with distance correction followed by $-3.0 \mathrm{D}$ added to distance correction for near fixating. The ACD shift was calculated subtracting the two mean values.

\section{Method 3: ACD measuring in near fixation followed by pharmacologically induced maximal ciliary muscle relaxation}

The ACD was measured during fixation with the contralateral eye at $30 \mathrm{~cm}$ and after instillation of
$1 \%$ cyclopentolate hydrochloride, administered three times at 15-min intervals. All patients were seated, with their heads vertical and their eyes level during the measurements to ensure that IOL movements were only produced by ciliary muscle activity. ACD measurements were performed by contact A-scan (Ultrascan Imaging System $^{\circledR}$, Alcon Laboratories, Forth Worth, TX, USA). The average of 10-10 measurements was presented as the ACD value. ACD shift was calculated by subtracting ACD under cyclopentolate from ACD during near fixation, corresponding to maximal ciliary relaxation and physiological ciliary contraction.

Statistical analysis was performed using SPSS 11.0 software, the data were described as mean \pm SD. The differences in values between methods were recorded with the unpaired test of Wilcoxon and a P-value of 0.05 was considered as the level of significance. The association between values were described with Spearman's correlation of rho $(r)$.

\section{Results}

The best-corrected visual acuity was $0.88 \pm 0.2$ in a decimal scale. The mean of distance correction was $-0.92 \pm 0.91 \mathrm{D}$. It was $-0.93 \pm 0.99 \mathrm{D}$ in the one-piece group and was $-0.77 \pm 0.82 \mathrm{D}$ in the three-piece group. The difference was not significant between these two groups $(P=0.44)$. The axial length was $22.54 \pm 0.89 \mathrm{~mm}$. It was $22.68 \pm 0.81 \mathrm{~mm}$ in the one-piece group and was $22.46 \pm 0.96 \mathrm{~mm}$ in the three-piece group. There were no statistically significant difference in axial length between the two groups $(P=0.68)$.

\section{Subjective minus-lenses-to-blur}

The largest minus lens with which the 20/20 line was just readable by the patient was $-0.83 \pm 0.63 \mathrm{D}$. It was $-0.95 \pm 0.67 \mathrm{D}$ (range: $-2.5-0.0 \mathrm{D}$ ) in the one-piece group and was $-0.81 \pm 0.53 \mathrm{D}$ (range: $-2.0-0.0 \mathrm{D}$ ) in the threepiece group. The difference between the two groups was not significant $(P=0.4)$.

\section{ACD measurement with a new device working with PCI technique}

ACD shift measured under physiological conditions was $-0.026 \pm 0.134 \mathrm{~mm}$. It was $-0.043 \pm 0.193 \mathrm{~mm}$ (range: -1.038 to $0.298 \mathrm{~mm}$ ) in the one-piece group and was $0.014 \pm 0.079 \mathrm{~mm}$ (range: -1.063 to $0.385 \mathrm{~mm}$ ) in the three-piece group. The difference between the one-piece and three-piece group was not significant $(P=0.46)$. The data are summarized in Table 1. 
Table 1 Amplitude of accommodation measured with a subjective method and with a PCI device under physiological conditions and the movement of the IOLs measured with A-scan ultrasound before and after cycloplegia

\begin{tabular}{lccc}
\hline & $\begin{array}{c}\text { Minus-lenses- } \\
\text { to-blur (D) }\end{array}$ & $\begin{array}{c}\text { ACD shift } \\
\text { measured } \\
\text { physiologically } \\
\text { with PCI using } \\
\text { physiological } \\
\text { stimulus ( } \mathrm{mm} \text { ) }\end{array}$ & $\begin{array}{c}\text { ACD shift } \\
\text { measured with } \\
\text { ultrasound } \\
\text { (between before } \\
\text { and after } \\
\text { cyclegia) (mm) }\end{array}$ \\
\hline One-piece IOL & $-0.95 \pm 0.67$ & $-0.043 \pm 0.193$ & $-0.16 \pm 0.3$ \\
Three-piece IOL & $-0.81 \pm 0.53$ & $0.014 \pm 0.079$ & $-0.2 \pm 0.28$ \\
All & $-0.83 \pm 0.63$ & $-0.026 \pm 0.134$ & $-0.18 \pm 0.28$ \\
\hline
\end{tabular}

$\mathrm{ACD}=$ anterior chamber depth; $\mathrm{IOL}=$ intraocular lense; $\mathrm{PCI}=$ partial coherence interference.

Positive values represent forward, and negative values represent backward movement of IOLs.

\section{ACD measurement with A-scan ultrasound in near fixation followed by pharmacologically induced maximal ciliary muscle relaxation}

ACD shift was $-0.18 \pm 0.28 \mathrm{~mm}$. It was $-0.16 \pm 0.3 \mathrm{~mm}$ (range: -0.51 to $0.2 \mathrm{~mm}$ ) in the one-piece group and was $-0.2 \pm 0.28 \mathrm{~mm}$ (range: -0.49 to $0.1 \mathrm{~mm}$ ) in the threepiece group. The difference between the one-piece and three-piece groups was not significant $(P=0.68)$.

There was no significant statistical correlation between pharmacologically induced ACD shift values and the diopter value of minus-lenses-to-blur method (Spearman's rho $(r)=0.16, P=0.37$ ).

\section{Discussion}

Certain patients with monofocal IOL can achieve good visual acuity for distance and for near with distance correction. This phenomenon is previously known as apparent accommodation. ${ }^{14}$ The amplitude of apparent accommodation varies significantly from patient to patient. Previous studies confirmed that the amplitude of apparent accommodation is correlated with depth of focus, ${ }^{15,16}$ pupil diameter, ${ }^{17-20}$ and degree of corneal astigmatism. $^{21-25}$

There are many studies about the forward movement of various types of IOLs during accommodation effort. ${ }^{6-10}$ However, the backward movement is possible with accommodative (AT-45 Crystalens) ${ }^{26}$ or with other types of IOLs. ${ }^{9}$ The phenomenon based on movement of an IOL is referred as pseudophakic accommodation. The common principle of the true pseudophakic accommodation is the ciliary muscle constrictionmediated movement of the IOL along the axis of the eye.

Many former studies have measured accommodative amplitude subjectively and objectively in pseudophakic eyes. ${ }^{27-30}$ The subjective methods depend on patient cooperation and are a sum of the amplitude of pseudophakic accommodation and pseudoaccommodation. The objective methods with different ciliary muscle medications (pilocarpin or cyclopentolate) can overestimate the actual IOL movement as it is shown possible in the recent study too.

Measuring the pseudophakic accommodation and pseudoaccommodation is an interesting and challenging task: what method should be used for measuring accommodative amplitude of the pseudophakic eyes and which method is the most accurate? Langenbucher $e t a l^{31}$ divide the possible techniques for measuring pseudophakic accommodation into groups and subgroups. According to their study, there is static, dynamic, as well as objective and subjective methods. In our study, we chose a dynamic, subjective method, the minus-lenses-to-blur method, and two static, objective, indirect methods, measuring the ACD with standard A-scan ultrasound and with ACMaster ${ }^{\mathbb{R}}$ under desaccommodative and accommodative condition with and without eye drop-induced ciliary muscle relaxation. However, subjective methods do not report differences between true pseudophakic accommodation and pseudoaccommodation.

Our data about the cycloplegia-induced-ACD shift is comparable with the values of literature in case of both types of IOLs. ${ }^{6,8-10}$ According to Nawa et al, ${ }^{32}$ it is an equivalent of approximately $0.3-0.35 \mathrm{D}$ of pseudophakic accomodation at an axial length of $22.54 \pm 0.89 \mathrm{~mm}$. It is about a third of that measured with subjective minuslenses-to-blur method. So the detected ACD shifts were too small for itself to explain the actual, subjective accommodation amplitude.

Objective methods is based on measuring the ACD thereby the position of the IOL in the two marginal accommodative conditions. The ACD can be measured with different ophthalmological techniques, such as ultrasound biometry, high-resolution magnetic resonance imaging, ultrasound biomicroscopy, Scheimpflug imaging, anterior segment optical coherence tomography, and partial coherence interferometry. ${ }^{31,33,34}$ We used objective measurements with a newly developed high accuracy interferometric device.

Almost every method for measuring pseudophakic accommodation and pseudoaccommodation has considerable potential for evaluating error. ${ }^{35}$ Therefore, measuring amplitude of accommodation in pseudophakic eyes poses some problems. Inducing accommodation with miotic eye drops causes strong pupillary miosis, so measuring through small pupils are difficult with some methods including PCI. Pupil dilation without causing cycloplegia (phenylephrine) induces greater high-order aberrations, ${ }^{36}$ with 
cycloplegic drugs (cyclopentolate) measurements are relatively easy, but the ability of the patients to deliver a normal accommodative response may decrease. Besides all of these, the eye drop-induced ciliary muscle constriction or relaxation shows only a maximum possibility of IOL movement, but does not represent the actual, physiologically produced pseudophakic accommodation.

This major disparity is well demonstrated in our study. The differences between the values of our three methods measuring pseudophakic accommodation are rather significant. Physiologically (PCI) there was no IOL movement neither in the one-piece nor in the three-piece group, with pharmacologically relaxed ciliary muscle, there was a mean of $0.3-0.35 \mathrm{D}$ enforced pseudophakic accommodation. With subjective method, a mean of $-0.83 \mathrm{D}$ was measured as total accommodation amplitude. It is an aggregate of pseudoaccommodation and pseudophakic accommodation amplitudes, and means that approximately $0.5 \mathrm{D}$ is probably achieved by the combination of the above-mentioned and other factors, such as patients' motivation and potential of visual perception.

Our two IOLs have different configurations: the Alcon ${ }^{\circledR}$ Acrysof ${ }^{\circledR}$ MA60AC IOL has $10^{\circ}$ angulation between haptic and optic, the Alcon ${ }^{\circledR}$ Acrysof ${ }^{\circledR}$ SA60AT IOL has an open-loop design without haptic angulation. Despite this fact, we did not observe any difference between diopter values of accommodation amplitude measured with any methods.

In conclusion, we demonstrated that different measurement methods of amplitude of accommodation with two types of monofocal IOLs show significant variance and are not comparable with each other.

\section{References}

1 Huber C. Myopic astigmatism: a substitute for accommodation in pseudophakia. Doc Ophthalmol 1981; 52: 123-178.

2 Trindade F, Oliveira A, Frasson M. Benefit of against-therule astigmatism to uncorrected near acuity. J Cataract Refract Surg 1997; 23: 82-85.

3 Nakazawa M, Ohtsuki K. Apparent accommodation in pseudophakic eyes after implantation posterior chamber intraocular lenses: optical analysis. Invest Ophthalmol Vis Sci 1984; 25: 1458-1460.

4 Fukuyama M, Oshika T, Amano S, Yoshitomi F. Relationship between apparent accommodation and corneal multifocality in pseudophakic eyes. Ophthalmology 1999; 106: 1178-1181.

5 Oshika T, Mimura T, Tanaka S, Amano S, Fukuyama M, Yoshitomi F et al. Apparent accommodation and corneal wavefront aberration in pseudophakic eyes. Invest Ophthalmol Vis Sci 2002; 43: 2882-2886.
6 Hardman Lea SJ, Rubinstein MP, Haworth SM. Pseudophakic accommodation? A study of the stability of capsular bag supported, one piece, rigid tripod, or seft flexible implants. Br J Ophthalmol 1990; 74: 22-25.

7 Gonzalez F, Capeans C, Santos L, Suarez J, Cadarso L. Anteroposterior shift in rigid and soft implants supported by the intraocular capsular bag. Graefe's Arch Clin Exp Ophthalmol 1992; 230: 237-239.

8 Lesiewska-Junk H, Kaluzny J. Intraocular lens movement and accommodation in eyes of young patients. J Cataract Refract Surg 2000; 26: 562-565.

9 Findl O, Kiss B, Petternel V, Menapace R, Georgopoulos M, Rainer $\mathrm{G}$ et al. Intraocular lens movement caused by ciliary muscle contraction. J Cataract Refract Surg 2003; 29: 669-676.

10 Findl O, Kriechbaum K, Menapace R, Koeppl C, Sacu S, Wirtitsch $\mathrm{M}$ et al. Laserinterferometric assessment of pilocarpine-induced movement of an accommodating intraocular lens. Ophthalmology 2004; 111: 1515-1521.

11 Fercher AF, Mengedoth K, Werner W. Eye length measurement by interferometry with partially coherent light. Opt Lett 1988; 13: 186-188.

12 Hitzenberger CK, Baumgartner A, Drexler W, Fercher AF. Interferometric measurement of corneal thickness with micrometer precision. Am J Ophthalmol 1994; 118: 468-476.

13 Drexler W, Baumgartner A, Findl O, Hitzenberger CK, Sattmann H, Fercher AF. Submicrometer precision biometry of the anterior segment of the human eye. Invest Ophthalmol Vis Sci 1997; 38: 1304-1313.

14 Betman JW. Apparent accommodation in aphakic eyes. Am J Ophthalmol 1950; 33: 921-928.

15 Elder MJ, Murphy C, Sanderson GF. Apparent accommodation and depth of field in pseudophakia. J Cataract Refract Surg 1996; 22: 615-619.

16 Niessen AGJE, de Jong LB, van der Heijde GL. Pseudoaccommodation in pseudophakia. Eur J Implant Refract Surg 1992; 4: 91-94.

17 Nakazawa M, Ohtsuki K. Apparent accommodation in pseudophakic eyes after implantation of posterior chamber intraocular lenses. Am J Ophthalmol 1983; 96: 435-438.

18 Nakazawa M, Ohtsuki K. Apparent accommodation in pseudophakic eyes after implantation of posterior chamber intraocular lenses: optical analysis. Invest Ophthalmol Vis Sci 1984; 25: 1458-1460.

19 Ravalico G, Baccara F. Apparent accommodation in pseudophakic eyes. Acta Ophthalmol 1990; 68: 604-606.

20 Elder MJ, Murphy C, Sanderson GF. Apparent accommodation and depth of field in pseudophakia. J Cataract Refract Surg 1996; 22: 615-619.

21 Huber C. Planned myopic astigmatism as a substitute for accommodation in pseudophakia. J Am Intraoc Implant Soc 1981; 7: 244-249.

22 Sawusch MR, Guyton DL. Optimal astigmatism to enhance depth of focus after cataract surgery. Ophthalmology 1991; 98: 1025-1029.

23 Datiles MB, Gancayco T. Low myopia with low astigmatism correction gives cataract surgery patients good depth of focus. Ophthalmology 1990; 97: 922-926.

24 Hillman JS, Bradbury JA. Apparent accommodation by myopic astigmatism with monofocal intraocular lenses. Eur J Implant Refract Surg 1990; 2: 101-104.

25 Huber C. Myopic astigmatism as a substitute for accommodation in pseudophakia. Dev Ophthalmol 1981; 5: 17-26. 
26 Koeppl C, Findl O, Menapace R, Kriechbaum K, Wirtitsch $\mathrm{M}$, Buehl W et al. Pilocarpine-induced shift of an accommodating intraocular lens: AT-45. Crystalens J Cataract Refract Surg 2005; 31: 1290-1297.

27 Rosenfield M, Portello JK, Blustein GH, Jang C. Comparison of clinical techniques to assess the near accommodative response. Optom Vis Sci 1996; 73: 382-388.

28 Rosenfield M, Cohen AS. Repeatability of clinical measurements of the amplitude of accommodation. Ophthalmic Physiol Opt 1996; 16: 247-249.

29 Kragha IKOK. Amplitude of accommodation: population and methodological differences. Ophthalmic Physiol Opt 1986; 6: 75-80.

30 Rutstein RP, Fuhr PD, Swiatocha J. Comparing the amplitude of accommodation determined objectively and subjectively. Optom Vis Sci 1993; 70: 496-500.

31 Langenbucher A, Huber S, Nguyen NX, Seitz B, Gusek-Schneider GC, Kuchle M. Measurement of accommodation after implantation of an accommodating posterior chamber intraocular lens. J Cataract Refract Surg 2003; 29: 677-685.

32 Nawa Y, Ueda T, Nakatsuka M, Tsuji H, Marutani H, Hara Y et al. Accommodation obtained per $1.0 \mathrm{~mm}$ forward movement of a posterior chamber intraocular lens. J Cataract Refract Surg 2003; 29: 2069-2072.

33 Findl O, Drexler W, Menapace R, Bobr B, Bittermann S, Vass $C$ et al. Accurate determination of effective lens position and lens-capsule distance with 4 intraocular lenses. J Cataract Refract Surg 1998; 24: 1094-1098.

34 Findl O, Drexler W, Menapace R, Hitzenberger CK, Fercher AF. High precision biometry of pseudophakic eyes using partial coherence interferometry. J Cataract Refract Surg 1998; 24: 1087-1093.

35 Whitefoot H, Charman WN. Dynamic retinoscopy and accommodation. Ophthalmic Physiol Opt 1992; 12: 8-17.

36 Carkeet A, Velaedan S, Tan YK, Lee DY, Tan DT. Higher order ocular aberrations after cycloplegic and noncycloplegic pupil dilation. J Refract Surg 2003; 19: 3106-3322. 